STUDIA UBB PSYCHOL.-PAED., LXVI, 1, 2021, p. 135 - 155

(Recommended Citation)

DOI:10.24193/subbpsyped.2021.1.07

\title{
CHARACTERISTICS OF ONLINE LEARNING IN HIGHER EDUCATION DURING THE COVID-19 PANDEMIC
}

\author{
DIANA-CRINA MARIN1*', MUȘATA BOCOȘ²
}

\begin{abstract}
In the context in which the teaching, learning, and assessment processes take place in the online environment, the question arises whether the currently organized learning situations are as effective as the learning situations carried out in the classroom, before the beginning of the pandemic. One of the disadvantages of online learning is related to the teacher's low control over students' activity. Factors such as initiative, creativity, efficient time management, intrinsic motivation, responsibility, and intellectual curiosity play an important role in students' success in learning activities. Attendance at courses should not be formal and superficial and should be a process that involves the active and interactive participation of the students in the learning process. Providing high-quality educational opportunities to all students is a goal that is increasingly difficult to achieve in the context of the absence of face-to-face interactions. Also, applying a curriculum focused on the needs of the learner is becoming hard to achieve. Through this research, we aim to investigate issues related to how online learning takes place and to establish ways in which we can increase the efficiency of current teaching and learning processes. The study revealed that in the opinion of most of the students, the current epidemiological context has influenced in a negative way the quality of teaching and the student-teacher educational relationship.
\end{abstract}

Keywords: Interactive learning, eLearning, independence in learning, higher education, efficient strategies

\footnotetext{
1 Babeș-Bolyai University, Doctoral School "Education, Reflection, Development", Cluj-Napoca, Romania

2 Babeș-Bolyai University, Faculty of Psychology and Educational Sciences, Cluj-Napoca, Romania

* Corresponding author: crinadiana88@yahoo.com
} 


\section{Theoretical Foundation}

The pandemic period raises challenges for both pre-university and university education related to conception, design, and development, in terms of promoting educational paradigms and principles that have systematically proven their value: active and interactive learning, learning-centered on educable, collaborative learning, differentiation and individualization of training, lifelong learning, and adult education. Referring to university education, we summarize these paradigms and action principles.

The main benefit provided by the online learning situations is the opportunity offered to all the students to study anytime or anywhere they want (Sujarwo, Sukmawati, Akhiruddi, Ridwan \& Siradjuddin, 2020; Garrison, Anderson \& Archer, 2000; Mukhtar, Javed, Arooj \& Sethi, 2020). Various applications and communication platforms are used with success to facilitate student-student interactions (Sujarwo, Sukmawati, Akhiruddi, Ridwan \& Siradjuddin, 2020; Meishar-Tal, Kurtz \& Pieterse, 2012). In the context of online learning, students' level of motivation for learning can be influenced by many factors, including cross-cultural differences (Lim, 2004). The Flipped Classroom Model is considered a beneficial practice that has positive effects on student's performance. Also, this method influences in a positive manner the level of satisfaction of the students (Schwarzenberg, Navon \& Pérez-Sanagustín, 2020; Mukhtar, Javed, Arooj \& Sethi, 2020). Individualization of training is an important factor that ensures the success of learning processes realized both in the classroom and in the online environment, and facilitates the achievement of positive learning experiences. (Azevedo \& Hadwin, 2005).

Learner-centered and cooperative learning are two of the concepts frequently used in the context of adult education (Crowe, 2000). Interindividual differences are factors that must be taken into account and that can ensure the success or failure of students' learning processes, even in the context of distance learning (Atman, 1988). Computer mediated-communication has many advantages, but this type of communication is not efficient in maintaining and developing close educational relationships between students and teachers. However, it allows for effective information exchange, creating a learning community in which members can offer emotional support and interact effectively and positively (Hiltz \& Wellman, 1997). Evaluation is a complex process. In the absence of face-to-face interactions, monitoring students' performance becomes a more difficult to achieve process. Self-assessment has an important role and contributes to optimizing learning processes (Boud, 1995). 
Garrison, Anderson \& Archer (2000) developed the Community of Inquiry model and showed that cognitive presence, social presence, and teaching presence are three essential elements that can ensure learning efficiency. Collaborative learning is considered an effective method to provide high-quality learning experiences for students. Students learn from each other and their support is offered in order to achieve the success of the entire team (Gokhale, 1995). The variety of interactions between learners is associated with a higher level of satisfaction in learning (Fulford \& Zhang, 1993).

The study conducted by Vate-U-Lan (2020) revealed that the well-being of the students could be a predictor of their attitudes towards e-learning. Thus, both face-to-face learning contexts and online learning situations generate positive learning experiences and offer multiple satisfactions (Allen, Bourhis, Mabry, Burrell \& Mattrey, 2002). The technological tools used in the teaching process influence the quality of students' learning experiences (Beldarrain, 2006). Asynchronous applications are used successfully in the context of distance learning, allowing students to use the learning materials provided by teachers whenever and wherever they want (Bernard et al., 2004).

The variety and authenticity of interpersonal interactions make cooperative learning an effective strategy, taking into account the results of numerous studies (Johnson \& Johnson, 2009; Lou, Abrami \& d'Apollonia, 2001). Concerns about the possibility of providing students with high-quality opportunities for social interaction and genuine dialogue have existed and continue to exist, although communication channels have become more effective (Muirhead, 2001). Researchers from all over the world have conducted a series of research in order to establish whether distance learning activities carried out in the online environment can be as effective as traditional face-to-face learning situations (Johnson, Aragon, Shaik, \& Palma-Rivas, 2000). Perceptions of the students regarding the teacher's activity and the quality of teacher-student interactions indicate that the learning activities, which take place in the university space are more efficient (Johnson, Aragon, Shaik \& Palma-Rivas, 2000). Regarding the quality and efficiency of online training, recent studies have shown that online courses could be considered, in most cases, as efficient as traditional ones (Mukhtar, Javed, Arooj \& Sethi, 2020). However, assessing students' competencies becomes more difficult. The level of knowledge is the only component of competencies that is easier to assess in the online environment (Mukhtar, Javed, Arooj \& Sethi, 2020).

The interactive character of the courses is one of the factors that facilitate the achievement of the educational objectives (Zirkin \& Sumler, 1995). In the context of the COVID-19 pandemic, organizing interactive and active learning and teaching situations in the online environment is beneficial. Interactions 
between students and teachers are very important, and expository teaching methods are less effective. The students' digital skills are already formed, and the learning situations that are usually organized, are flexible and involve the active participation of the students. Organizing courses in this way reduce significantly the effects of this pandemic (Sadikin \& Hamidah, 2020). Giguere \& Minotti (2003) have mentioned some of the factors that need to be taken into account in designing online learning situations: differentiation and individualization of training, clear formulation of objectives and expectations, presentation of content in a varied and attractive way, selecting contents adequate and accessible and creating a learning environment that stimulates positive interactions between students. Globalization, the diversity of the needs and interests of the students, as well as technological developments, are the main factors that contribute to the increasing number of students who are enrolled in online courses. (Storey \& Tebes, 2008; Morey, 2004).

\section{Research Methodology}

An original online questionnaire was administered in order to establish which are the solutions that can be applied to optimize the online learning processes in higher education during the COVID-19 pandemic (see the appendix of this paper). The questionnaire was completed by 425 students that are enrolled in university programs from the field of Educational Sciences. 282 of them are enrolled in undergraduate university programs, while the remaining 143 attend a master's degree programs. Through this study, we aimed to investigate students' views on how online learning situations are organized in higher education.

\section{Results}

The majority of the students appreciated the fact that in the context in which the courses take place in the online environment, the quality of the teaching process is affected to a great extent (see figure 1). The students mentioned that the virtual interactions cannot be compared with the real ones and the fact that the face-to-face interactions are authentic. The notions presented are easier to understand if the connections take place face-to-face. Also, the level of motivation for learning becomes lower for some of the students in the context of online teaching. The assessment process is affected and the students have considered that only a superficial assessment of their competencies could be made. Assessment methods that can be applied to students are not 
associated with a qualitative and objective assessment. Student-student interaction is less effective, and the success of online learning situations can be achieved through much greater effort, both on the part of students and teachers. Some students pointed out that the teaching-learning process is affected to a different extent, depending on the study discipline, the subject of the course, or the difficulty of the learning contents. Technological impediments often arise in the teaching process, and the time required for teaching and learning becomes higher.

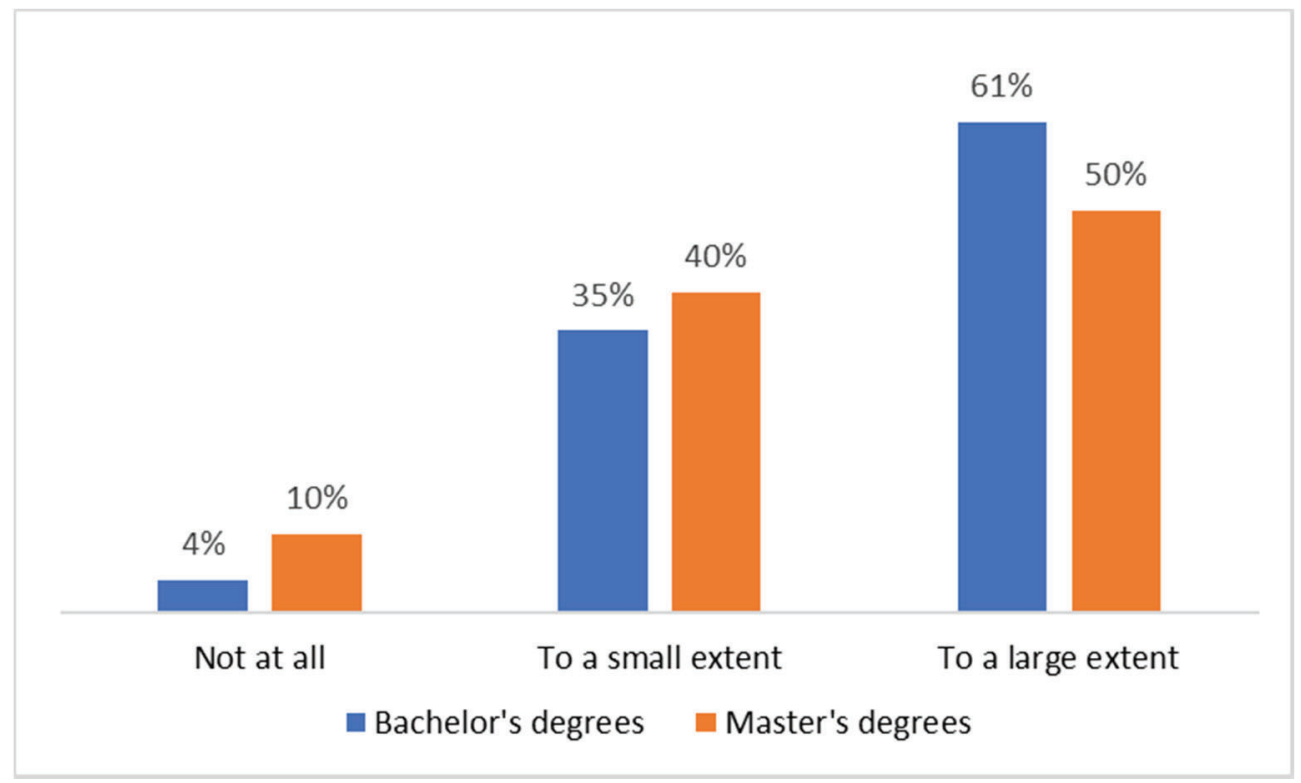

Figure 1. The extent to which the quality of the teaching act is affected

Regarding the way in which the teacher-student educational relationship is affected, most students appreciated that during online courses their educational relationship with their teachers was affected (see figure 2). Most of the students enrolled in the first year mentioned that they want to interact with teachers in a traditional way, in the university space. In the online environment, it is more difficult, but not impossible, to organize learning situations in which students interact in a positive way with teachers, requiring much more effort and desire from all educational actors. Thus, in the absence of physical contact, interpersonal interactions are affected. 
DIANA-CRINA MARIN, MUȘATA BOCOȘ

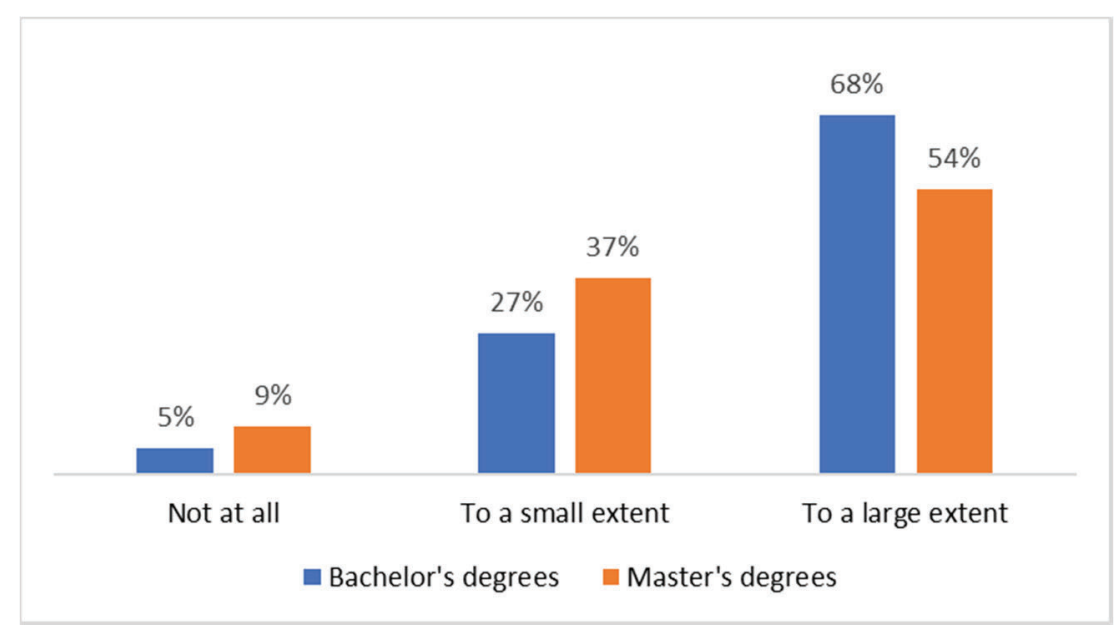

Figure 2. The extent to which the student-teacher educational relationship is affected

Most students know which are the topics or bibliographic resources that are used during the courses or seminars. Students are aware of the content of the activities that are planned and know what topics will be studied in the next courses or seminars (see figure 3 ).

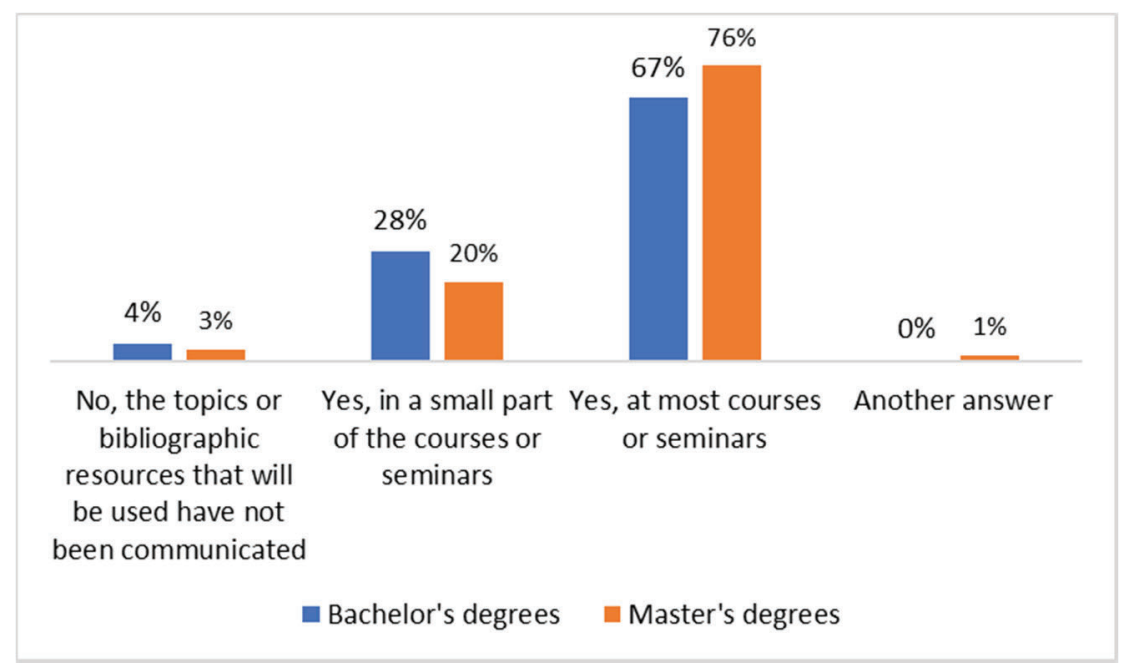

Figure 3. The extent to which students know the topics to be studied 
Most of the students converse with their teachers and colleagues using the educational platforms designed for the teaching process (see figure 4). 1\% of the respondents are contacting their teachers through accounts created on Facebook.

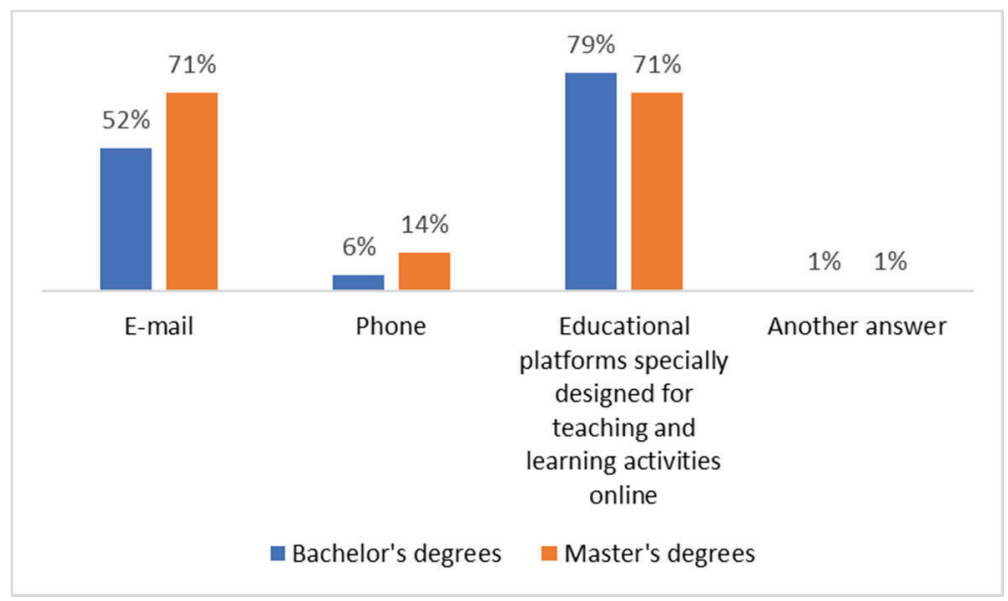

Figure 4. The means of communication used to contact teachers

Most respondents appreciated that most of the courses they attended online had a medium degree of difficulty (see figure 5).

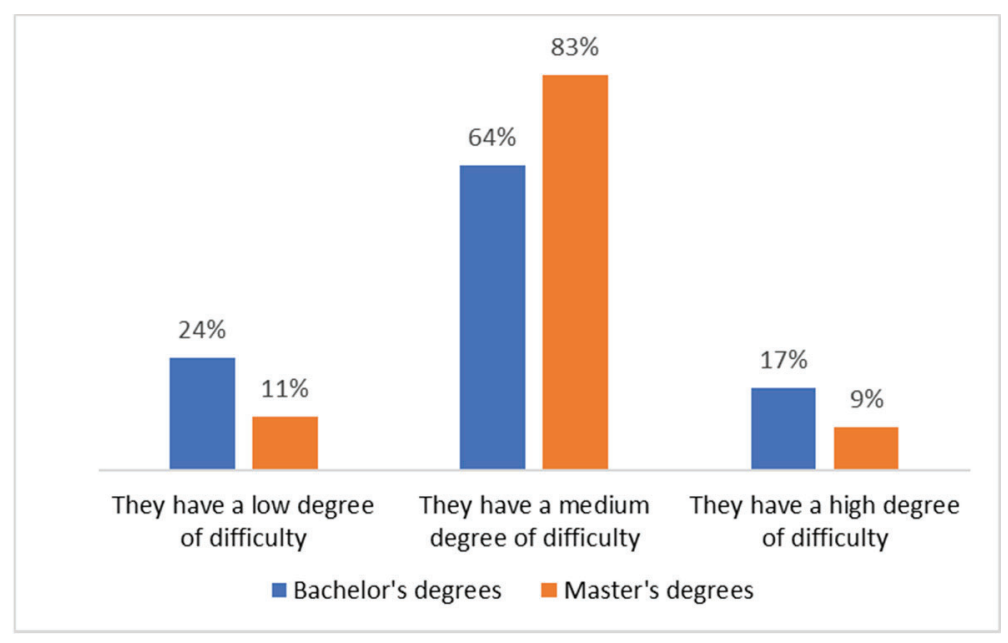

Figure 5. The degree of difficulty of online courses 
Most of the undergraduate degree students have indicated that they currently receive more learning tasks that involve cooperative or group learning activities, in comparison with the period when the courses took place face-to-face (before the beginning of this outbreak). At the same time, most of the master students gave a negative answer to question 6 and consider that interactive learning situations are not organized more frequently than before (see figure 6).

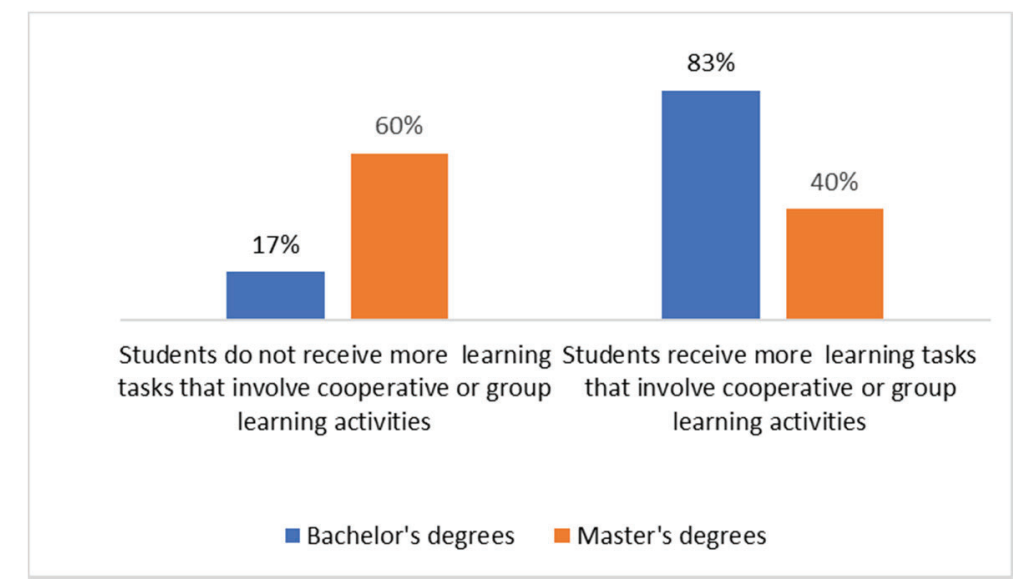

Figure 6. Frequency of the organization of the interactive learning situations

Most students use the WhatsApp instant messaging network to communicate with their peers during online courses (see figure 7). Also, groups created on Facebook or and other communication platforms were mentioned (Zoom and Google Meet).

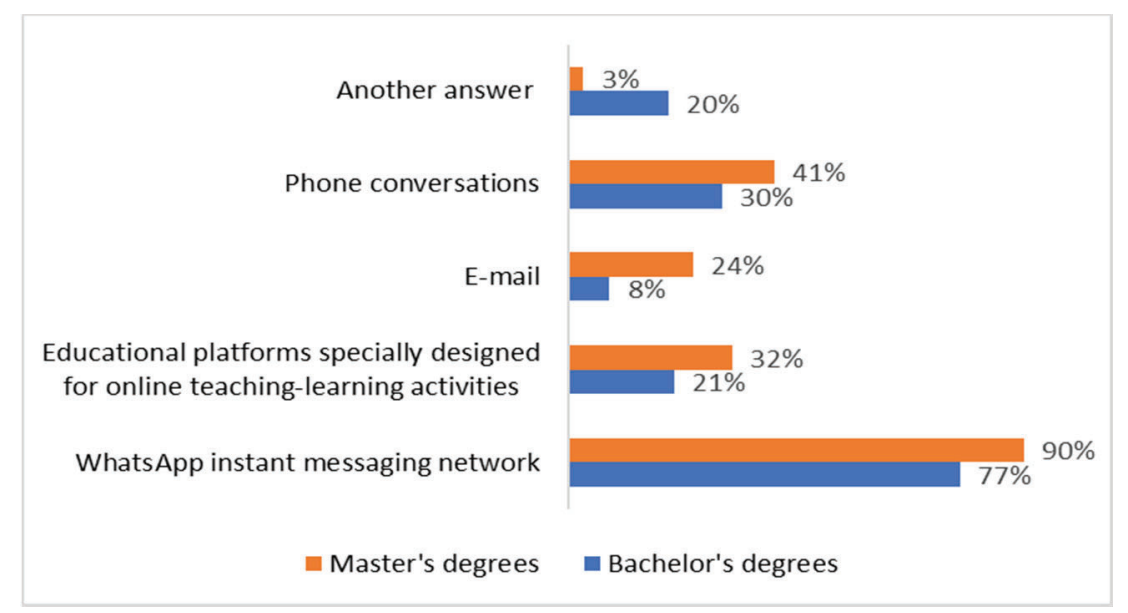

Figure 7. Channels used for communication with their colleagues 
Most bachelor students appreciate the fact that more emphasis is placed on their individual and independent activities. Many master students appreciate that they are not involved more frequently in individual learning situations (see figure 8).

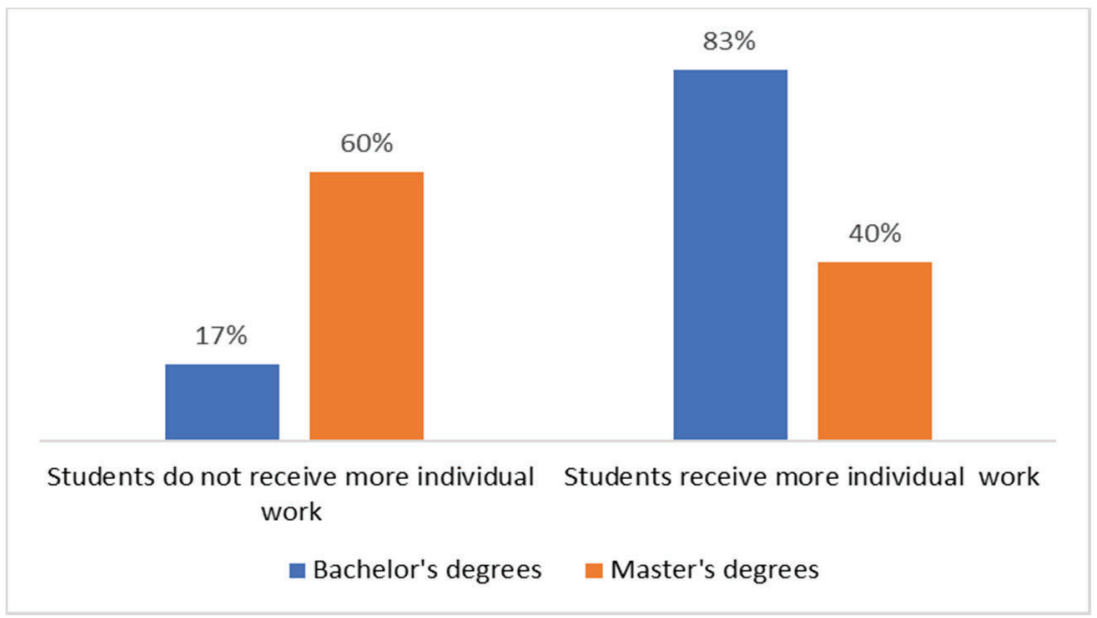

Figure 8. Aspects regarding the usage of the individual learning

Most undergraduate students indicated that they frequently receive work tasks that involve interactive learning activities (based on cooperation with other colleagues). Most master students mentioned that they work less often in teams and the fact that individual work tasks predominate (see figure 9).

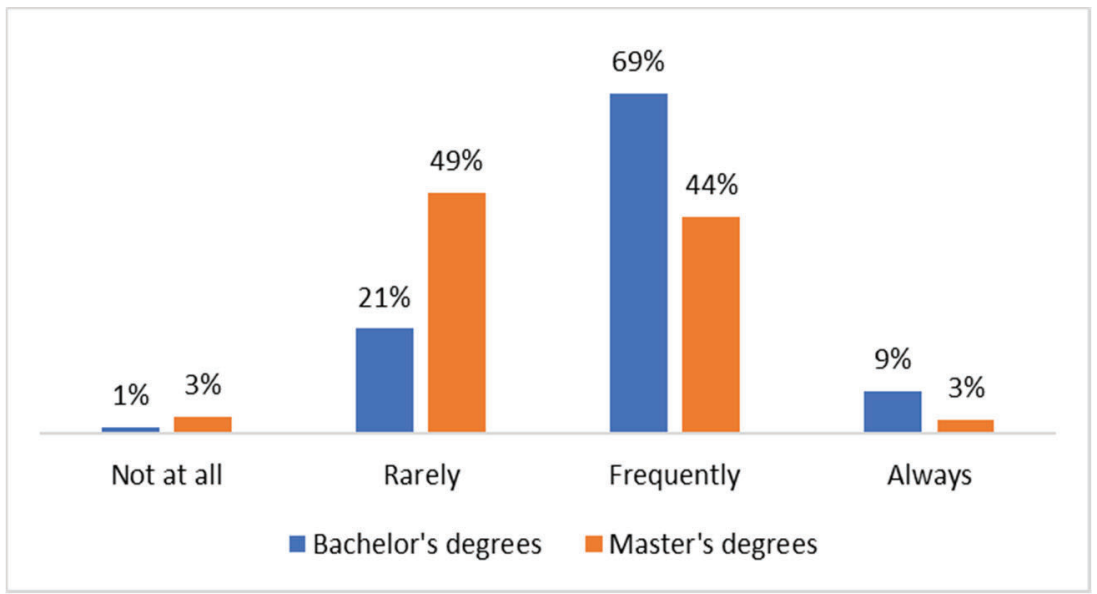

Figure 9. The frequency of the usage of interactive learning 
Regarding the degree of interactivity of the courses or seminars conducted in the online environment, in the students' opinion, most of the courses are based on the active involvement of students. Individual or independent work tasks are offered more frequently than group tasks (see figures 10 and 11).

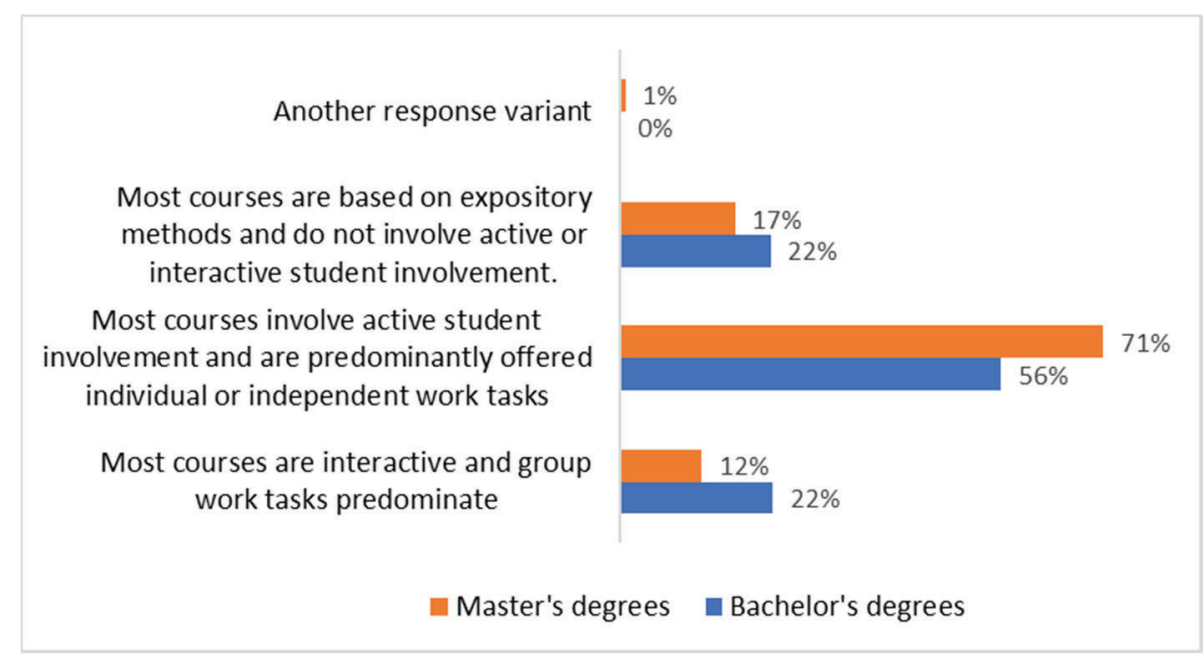

Figure 10. The characteristics of online courses

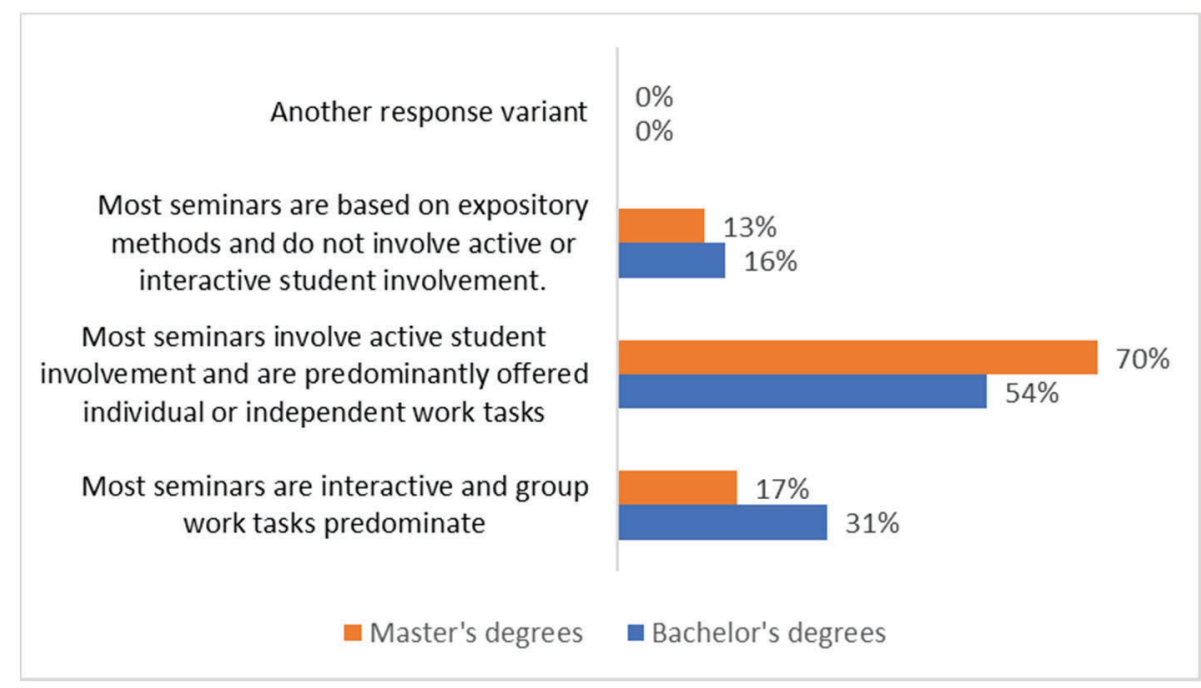

Figure 11. The characteristics of the online seminars 
Most students want to receive feedback frequently or always from teachers. Students mentioned that it is up to the teacher to decide how often it would be necessary to give them feedback. Also, most students have received frequently feedback from teachers (see figure 12 and 13).

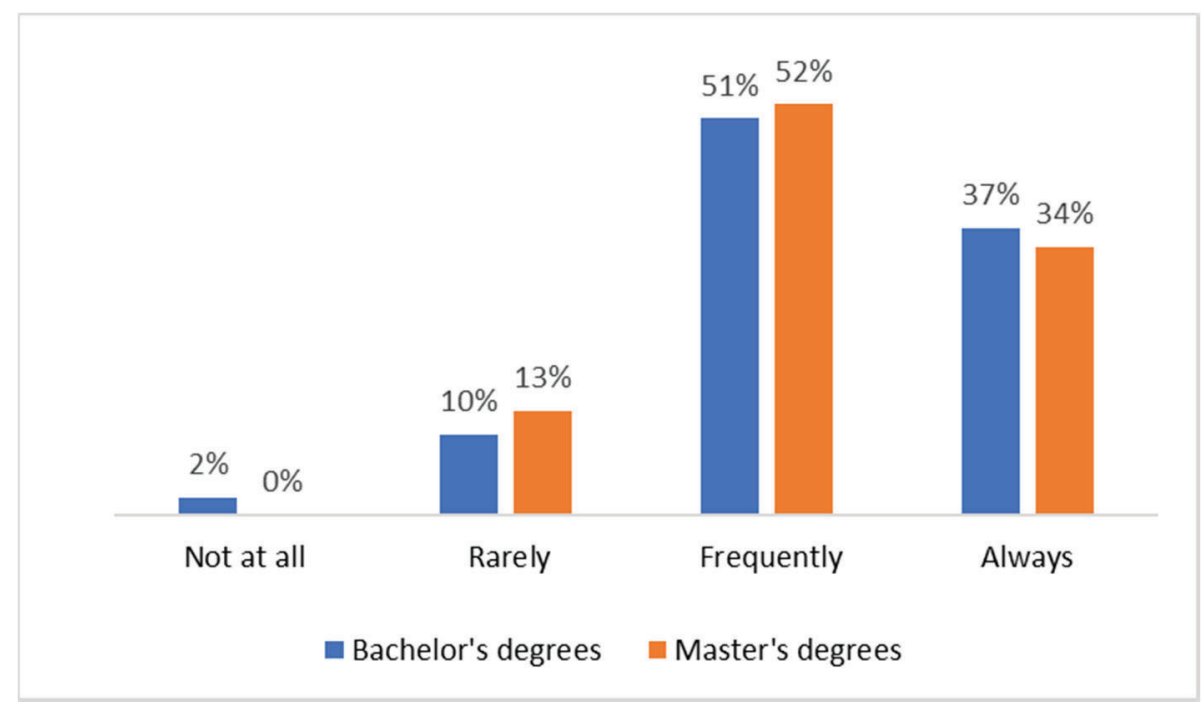

Figure 12. The frequency with which students want to receive feedback

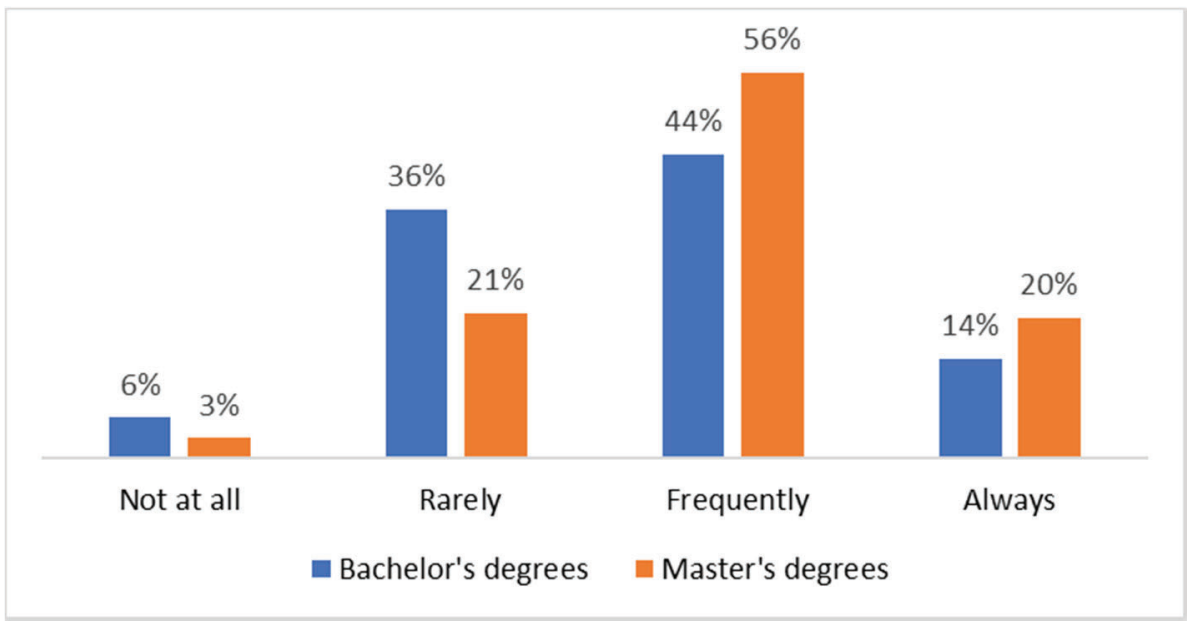

Figure 13. Students' opinion on the frequency with which they have received feedback from teachers 
Most of the master's students indicated that they devote less than 3 hours a day to learning activities. At the undergraduate level, the percentage of students who spend more than 3 hours a day is bigger than at the master's level (see figure 14).

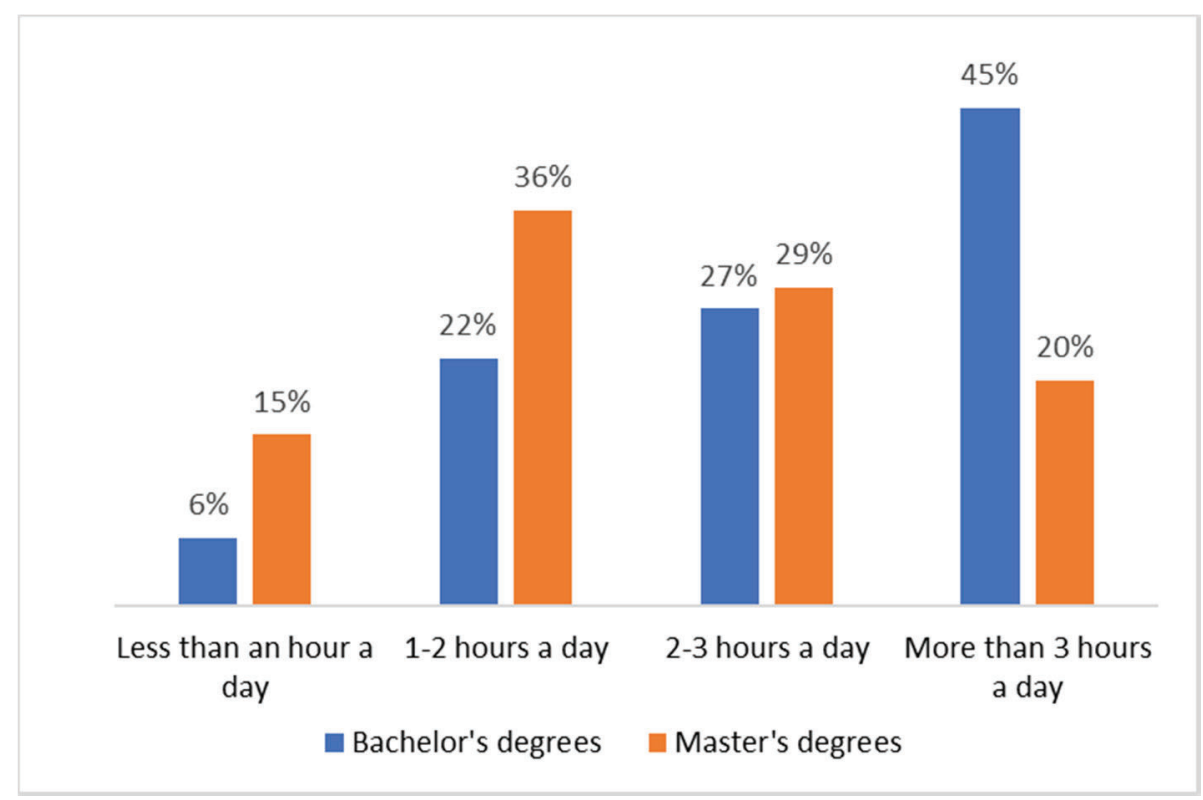

Figure 14. The amount of time allocated daily to learning activities

Only a small percentage of students (7\%, i.e., 23 undergraduate students, respectively $20 \%$, i.e. 28 master students) did not face any problems in the online learning process. The most frequently mentioned obstacles are technical difficulties connecting on certain platforms, physical fatigue, mental fatigue, and lack of internet access or connection problems (see table 1). Students who chose another answer mentioned obstacles, such as:

- difficulties concentrating;

- problems adapting to new training situations;

- physical implications caused by long-term use of the computer (e.g. migraines, back pain, and stinging of the eyes);

- incompatibility of teaching methods with students' learning style. 
Table 1. Problems encountered in the online teaching process

\begin{tabular}{|c|c|c|c|c|}
\hline \multirow[t]{2}{*}{ Main obstacles } & \multicolumn{2}{|c|}{$\begin{array}{c}\text { Bachelor's degree } \\
\text { programs }\end{array}$} & \multicolumn{2}{|c|}{$\begin{array}{l}\text { Master's degree } \\
\text { programs }\end{array}$} \\
\hline & Percentage & Frequency & Percentage & Frequency \\
\hline $\begin{array}{l}\text { Insufficient level of digital } \\
\text { skills }\end{array}$ & $14 \%$ & 43 & $12 \%$ & 17 \\
\hline $\begin{array}{l}\text { Lack of internet access or } \\
\text { connection problems }\end{array}$ & $44 \%$ & 138 & $24 \%$ & 34 \\
\hline $\begin{array}{l}\text { Lack of a high-performance } \\
\text { computer, tablet or phone }\end{array}$ & $11 \%$ & 34 & $7 \%$ & 10 \\
\hline $\begin{array}{l}\text { Technical difficulties in } \\
\text { connecting on certain } \\
\text { platforms }\end{array}$ & $40 \%$ & 125 & $40 \%$ & 57 \\
\hline Physical fatigue & $44 \%$ & 138 & $35 \%$ & 50 \\
\hline Mental fatigue & $71 \%$ & 222 & $52 \%$ & 74 \\
\hline $\begin{array}{l}\text { Emotional problems, related } \\
\text { to the suspension of the } \\
\text { university courses or to the } \\
\text { evolution of the current } \\
\text { epidemiological context }\end{array}$ & $26 \%$ & 81 & $18 \%$ & 26 \\
\hline Another response variant & $4 \%$ & 13 & $1 \%$ & 2 \\
\hline
\end{tabular}

$50 \%$ of the master's students appreciate the fact that online learning activities are effective and consider that this type of activity should be organized occasionally, even after the pandemic. $43 \%$ of the students mentioned that they do not like to carry out online learning activities. Students who chose a different answer showed that they do not consider online learning activities as effective as those done before this pandemic and that this type of activity should be done only when face-to-face interactions cannot be realized. Among the benefits mentioned by the respondents is the convenience of studying from home, without the need for travel and the efficiency of these activities from an economic point of view. According to the students, some educational activities (for example, webinars) should take place occasionally in the online environment (see figure 15). 
DIANA-CRINA MARIN, MUȘATA BOCOȘ

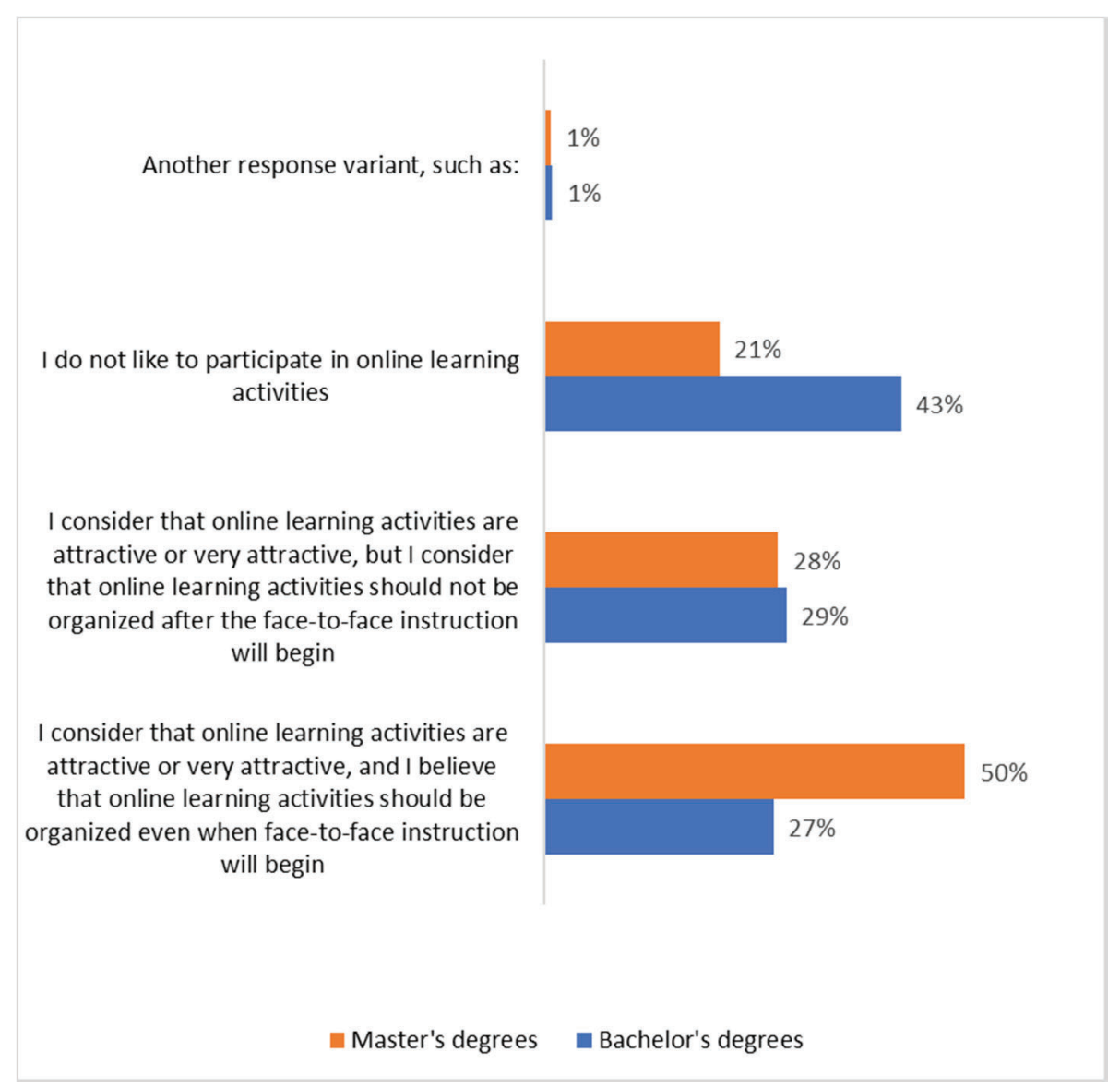

Figure 15. Students' opinion on the efficiency of online learning activities

Students consider that attendance at courses has been modified in the context of online teaching. At the master's level, most students consider that attendance at courses has become higher or has remained unchanged, while most undergraduate students have shown that attendance at courses has remained unchanged (see figure 16). 


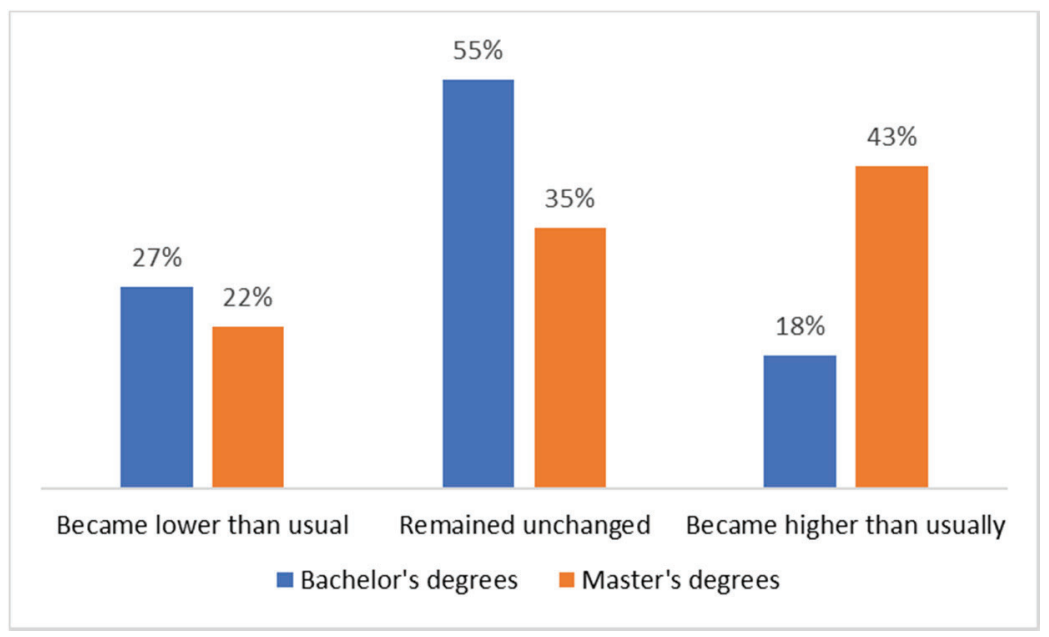

Figure 16. Students' opinion regarding the attendance on courses

The students have mentioned that attendance at courses can be influenced by factors such as the hour in which the course is organized, the period in which the course takes place (at the beginning, middle, or end of the semester), or its topic. Also, some of the respondents showed that when the participants have their video cameras and microphones turned off, is difficult to appreciate if they are actively involved in the learning activity. Some students mentioned that students' attention and involvement became lower, although attendance at courses could sometimes increase significantly.

\section{Discussions and Conclusions}

The results obtained indicate that online learning is not considered as effective as face-to-face interactions. At the same time, the students' opinions are various, but most of them revealed that the biggest disadvantage of online learning is related to interpersonal communication and building strong educational relationships. The main advantage of online learning is the increased accessibility of the courses and seminars for all students. In the students' opinion, at bachelor degree level are organized more frequently interactive learning situations. At the master degree level, the accent falls most of the time on students' independent and individual efforts in solving the learning tasks. Students are aware that teachers have changed their teaching strategies. Attendance in courses increased, but some of the respondents mentioned that they do not like to be involved in online courses. 
The study revealed that in absence of the face-to-face interactions the quality of the didactic act was affected. Some of the students have positive opinions and appreciate the value and the benefits provided by online learning, while others prefer face-to-face courses. The quality of the courses was not affected significantly, but the quality of interactions between students and teachers became lower in this context. In order to avoid physical or mental fatigue, learning situations should be attractive and accessible. Also, teachers could make more efforts in developing strong and effective relationships with their students, through discussions and interactive learning situations.

This investigation of the students' opinions related to online university education was conducted among undergraduate and master's students in the field of Educational Sciences. From a didactic point of view, the specifics of the contents in this field and the ways of their transmission and assimilation can be similar to those of the socio-human sciences. Through scientific pedagogical research, it will be possible to highlight possible similarities and differences and, implicitly, ways to improve the quality of the educational processes carried out in higher education.

\section{Acknowledgements}

We would like to thank all the participants for their support in conducting this study.

\section{REFERENCES}

Atman, K. (1988). Psychological type elements and goal accomplishment style: Implications for distance education. The American Journal of Distance Education, $2(3), 36-44$.

Azevedo, R., \& Hadwin, A.F. (2005). Scaffolding Self-Regulated Learning and Metacognition-Implications for the Design of Computer-Based Scaffolds. Instructional Science, 33(5-6), 367-379.

Beldarrain, Y. (2006). Distance Education Trends: Integrating new technologies to foster student interaction and collaboration. Distance Education, 27(2), 139-153.

Bernard, R.M., Abrami, P.C., Lou, Y., Borokhovski, E., Wade, A., Wozney, L., et al. (2004). How Does Distance Education Compare with Classroom Instruction? A MetaAnalysis of the Empirical Literature. Review of Educational Research, 3(74), 379-439.

Boud, D. (1995). Enhancing learning through self-assessment. London: Kogan Page.

Crowe, J.L. (2000). Evaluation of Adult Learners: Ethical Issues. New Horizons in Adult Education, 14(3), 4-10.

Fulford, C. P., \& Zhang, S. (1993). Perceptions of Interaction: The critical predictor in distance education. American Journal of Distance Education, 7(3), 8-21. 
Garrison, D.R., Anderson, T., \& Archer, W. (2000). Critical Inquiry in a Text-Based Environment: Computer Conferencing in Higher Education. The Internet and Higher Education, 2(2-3), 87-105.

Giguere, P., \& Minotti, J (2003). Developing High-Quality Web-Based Training for Adult Learners. Educational Technology, 43(4), 57-58.

Gokhale, A.A. (1995). Collaborative Learning Enhances Critical Thinking. Journal of Technology Education, 7(1). Retrieved December 15, 2020, from http://scholar.lib.vt.edu/ejournals/JTE/v7nl/gokhale.jte-v7nl.html.

Hiltz, S.R., \& Wellman, B. (1997). Asynchronous Learning Networks as a Virtual Classroom. Communications of the ACM, 40(9), 44-49.

Johnson, D. W., \& Johnson, R. T. (2009). An Educational Psychology Success Story: Social Interdependence Theory and Cooperative Learning. Educational Researcher, 368(5), 365-379. doi:10.3102/0013189X09339057.

Johnson, S.D., Aragon, D.R., Shaik, N., \& Palma-Rivas, N. (2000). Comparative Analysis of Learner Satisfaction and Learning Outcomes in Online and Face-to-Face Learning Environments. Journal of Interactive Learning Research, 11(1), 29-49.

Lim, D. (2004). Cross Cultural Differences in Online Learning Motivation. Educational Media International, 41(2), 163 - 175.

Lou, Y., Abrami, P. C., \& d'Apollonia, S. (2001). Small Group and Individual Learning with Technology: A Meta-Analysis. Review of Educational Research, 71(3), 449-521.

Meishar-Tal, H., Kurtz, G., \& Pieterse, E. (2012). Facebook Groups as LMS: A Case Study. The International Review of Research in Open and Distributed Learning, 13(4), 33-48.

Muirhead, B. (2001). Enhancing Social Interaction in Computer-Mediated Distance Education. USDLA Journal, 15(4). Retrieved from http://www.usdla.org/html/journal/APR01_Issue/article02.html.

Mukhtar, K., Javed, K., Arooj, M., \& Sethi, A. (2020). Advantages, Limitations and Recommendations for online learning during COVID-19 pandemic era. Pakistan Journal of Medical Sciences, 36, S27 - S31.

Sadikin, A., \& Hamidah, A. (2020). Pembelajaran Daring di Tengah Wabah Covid-19: (Online Learning in the Middle of the Covid-19 Pandemic). Biosilico, 6(2), 214224.

Schwarzenberg, P., Navon, J. \& Pérez-Sanagustín, M. (2020). Models to provide guidance in flipped classes using online activity. J Comput High Educ, 32, 282-306.

Storey, V. A., \& Tebes, M. L. (2008). Instructor's Privacy in Distance (Online) Teaching: Where do you draw the line? Online Journal of Distance Learning Administration, 11(2). Retrieved from http://www.westga.edu/ distance/ojdla/summer112/storey112.html.

Sujarwo, S, Sukmawati, S., Akhiruddin, A. \& Ridwan, R. \& Siradjuddin, S. (2020). An Analysis of University Students' Perspective On Online Learning in The Midst of Covid-19 Pandemic. Jurnal Pendidikan dan Pengajaran, 53(2), 125-137.

Vate-U-Lan, P. (2020). Psychological impact of e-learning on social network sites: online students' attitudes and their satisfaction with life. Journal of Computing in Higher Education, 32(6), 27-40. https://doi.org/10.1007/s12528-019-09222-1.

Zirkin, B., \& Sumler, D. (1995). Interactive or non-interactive? That is the question!!! An annotated bibliography. Journal of Distance Education, 10(1), 95-112. 


\section{Appendix A}

\section{Questionnaire regarding the use of online learning in higher education}

Through this study, we aim to investigate the students' opinions regarding the optimal solutions that can be applied to optimize the online learning processes achieved in higher education during the COVID-19 pandemic. To fill in this questionnaire takes a maximum of 5 minutes, and the answers are anonymous. The data collected will be statistically processed.

1. In the context in which the courses are taking place in the online environment, to which extent do you appreciate that the quality of the didactic act is affected?

$\Gamma$ Not at all

$\lceil$ To a small extent

$\ulcorner$ To a large extent

2. In the context in which the courses are taking place in the online environment, to what extent do you appreciate that the teacher-student educational relationship is affected?

$\lceil$ Not at all

Г To a small extent

$\ulcorner$ To a large extent

3. Do you know the topic or the bibliographic resources used in the following seminars or courses (Are the activities efficient planned so that you know what topics will be studied in the next courses or seminars?)?

$\Gamma \quad$ No, the topics or bibliographic resources that will be used have not been

communicated

$\ulcorner$ Yes, in a small part of the courses or seminars

$\lceil$ Yes, at most courses or seminars

$\ulcorner$ Another answer:

4. Which modality do you use to contact your teachers? (more possible answers)

$\ulcorner$ E-mail

$\lceil$ Phone

$\lceil$ Educational platforms specially designed for teaching and learning activities online

5. Which are the characteristics of the majority of the courses that you have participated in the online environment? (more possible answers)

$\ulcorner$ They have a low degree of difficulty 
$\ulcorner$ They have a medium degree of difficulty

$\ulcorner$ They have a high degree of difficulty

6. Do you consider that you currently receive more learning tasks that involve cooperative or group learning activities, compared to the period when the courses took place face-to-face before the epidemic started?

$\lceil$ Yes

$\Gamma$ No

7. What form of communication do you use to communicate with your colleagues during this time? (more possible answers)

$\lceil\quad$ WhatsApp instant messaging network

$\ulcorner$ Educational platforms specially designed for online teaching-learning activities

$\Gamma$ E-mail

$\lceil$ Phone conversations

$\ulcorner$ Another response variant, such as:

8. Do you consider that you currently receive more learning tasks that involve individual or independent work, compared to the situation in which the courses were run face-to-face before the outbreak began?

$\Gamma$ Yes

$\Gamma$ No

9. How often do you receive tasks that involve interactive learning activities (based on cooperation with other colleagues)?

$\lceil\quad$ Not at all

$\ulcorner$ Rarely

$\ulcorner$ Frequently

$\ulcorner$ Always

10. Regarding the degree of interactivity of the courses conducted in the online environment, I can state that:

$\lceil$ Most courses are interactive and group work tasks predominate

$\ulcorner$ Most courses involve active student involvement and are predominantly offered individual or independent work tasks

$\lceil$ Most courses are based on expository methods and do not involve active or interactive student involvement.

$\ulcorner$ Another response variant, such as: 
11. Regarding the degree of interactivity of the seminars conducted in the online environment, I can state that:

$\lceil$ Most seminars are interactive and group work tasks predominate

$\ulcorner$ Most seminars involve active student involvement and are predominantly offered individual or independent work tasks

$\lceil$ Most seminars are based on expository methods and do not involve active or interactive student involvement

$\ulcorner$ Another response variant, such as:

12. How often do you want to receive feedback from teachers about your progress in learning or about the way that you have solved the learning tasks?

$\Gamma$ Not at all

Г Rarely

$\ulcorner$ Frequently

$\ulcorner$ Always

13. How often do you have received feedback from teachers about your progress in the learning activities?

$\Gamma \quad$ Not at all

Г Rarely

$\ulcorner$ Frequently

$\ulcorner$ Always

14. How much time do you spend daily doing learning activities?

$\Gamma$ Less than an hour a day

ᄃ 1-2 hours a day

ᄃ 2-3 hours a day

ᄃ More than 3 hours a day

15. What problems did you encounter in the online learning process? (more possible answers)

$\ulcorner$ Insufficient level of digital skills

$\lceil$ Lack of internet access or connection problems

$\ulcorner$ Lack of a high-performance computer, tablet, or phone

$\Gamma$ Technical difficulties in connecting on certain platforms

$\lceil$ Physical fatigue

$\ulcorner$ Mental fatigue 
$\lceil$ Emotional problems, related to the suspension of the university courses or to the evolution of the current epidemiological context

$\ulcorner\quad$ I did not face any difficulties and the learning process is taking place in very good conditions

$\ulcorner$ Another response variant, such as:

16. What is your opinion about online learning?

$\Gamma$ I consider that online learning activities are attractive or very attractive, and

I believe that online learning activities should be organized even when face-to-face instruction will begin

$\lceil\quad$ I consider that online learning activities are attractive or very attractive, but

I consider that online learning activities should not be organized after the face-to-face instruction will begin

$\Gamma \quad$ I do not like to participate in online learning activities

$\ulcorner$ Another response variant, such as:

17. In your opinion the number of course participants decreased or become higher if the teaching activities take place online?

$\lceil$ Became lower than usual

$\lceil$ Remained unchanged

$\ulcorner$ Became lower than usually 